Filol. Linguíst. Port., Sáo Paulo, v. 17, n. 2, p. 539-568, jul./dez. 2015

http://dx.doi.org/10.11606/issn.2176-9419.v17i2p539-568

\title{
O processo de produção/adaptação de material didático de fonética e fonologia para deficientes visuais
}

\author{
The process of production/adaptation of phonetics and phonology's \\ didactic material for visual deficient
}

\author{
Edson Carlos Romualdo* \\ Universidade Estadual de Maringá, Maringá, Paraná, Brasil \\ Gabriela de Souza Marques** \\ Universidade Estadual de Maringá, Maringá, Paraná, Brasil
}

\begin{abstract}
Resumo: Este artigo apresenta o processo de produção/adaptação de material didático de fonética e fonologia para deficientes visuais, oriundo de uma pesquisa motivada pela ausência de meios para levar a uma acadêmica deficiente visual do curso de Letras da Universidade Estadual de Maringá (UEM) os símbolos fonéticos e fonológicos, uma vez que constituem conhecimentos fundamentais para o desenvolvimento profissional de futuros professores de língua materna. Diante dessa lacuna e a favor da inclusão, o intuito era vislumbrar a melhor forma de representar os símbolos. Para tanto, entrevistas semiestruturadas foram realizadas com profissionais da educação especial que trabalham com cegos, segundo os quais o Braille é o recurso mais eficaz no processo de ensino e aprendizagem de náo videntes. Assim, o resultado da pesquisa foi a adaptaçáo em Braille, feita pelo Centro de Apoio Pedagógico (CAP) de Maringá, de um livro acerca de fonética e fonologia - inclusive dos símbolos -, organizado com destinaçâo para a formação de professores.
\end{abstract}

* Professor associado de Linguística do Departamento de Teorias Linguísticas e Literárias da Universidade Estadual de Maringá, Maringá, Paraná, Brasil, ecromualdo@uol.com.br.

** Pesquisadora iniciante de Linguística do Departamento de Teorias Linguísticas e Literárias da Universidade Estadual de Maringá, Maringá, Paraná, Brasil, gsmarquespl@gmail.com. 
Palavras-chave: Fonética. Fonologia. Deficiência visual. Inclusão educacional. Ensino-aprendizagem. Braille.

Abstract: This paper describes the process of production and adaptation of phonetics and phonology teaching material for the visually impaired. The research was motivated by the lack of means to represent phonetic and phonological symbols to a visually impaired undergraduate student of the Language and Literature Course of Universidade Estadual de Maringá (UEM) [Maringá State University], Brazil, due to the fact that these symbols are elementary for the professional development of future Portuguese teachers. Considering this shortcoming and in favor of educational inclusion, the intention was to find the best method to represent these symbols. Half-structured interviews were undertaken with special education professionals who work with the visually impaired, which insisted that the Braille method is the most efficient resource for teaching and learning for these students. The result of this research was the adaptation to the Braille system, by professionals of the Centro de Apoio Pedagógico (CAP) [Center for Pedagogical Aid] in Maringá, of a book on phonetics and phonology, including symbols, organized for teachers' formation.

Keywords: Phonetics. Phonology. Visual deficiency. Educational inclusion. Teaching-Learning. Braille.

\section{INTRODUÇÃO}

No Brasil e em países da Europa e da América Latina em geral, o atendimento às pessoas com necessidades educacionais especiais aconteceu de modo desvinculado do atendimento àquelas que não apresentavam tais necessidades. Nesse sentido, segundo Kassar (2011), a educação especial tornou-se um campo de atuação específico, em que o professor era incumbido, por exemplo, de diferenciar, de acordo com designações publicadas em revista de educação brasileira em 1914, as crianças do tipo "inteligente normal médio" das do tipo "débil de espírito", por seus aspectos externos.

Entretanto, na década de 1950, passou-se a falar sobre inclusão social, conceito que abrange projetos, políticas, leis e serviços voltados ao atendimento de pessoas com necessidades especiais, de modo a integrá-las na sociedade, por meio da educação e do trabalho. Mais adiante, nos anos 1990, a Lei de Diretrizes e Bases da Educação Nacional (Lei no 9.394/1996) afirma, em seu capítulo V - que versa especificamente sobre educação especial -, Art. 58, que esta é uma modalidade da educação escolar oferecida preferencialmente na rede regular de ensino, e assegura direitos aos alunos com necessidades especiais como serviços de apoio, currículos, 
métodos, técnicas, recursos educativos e organização específicos para atenderem às suas necessidades.

A luta pela transformação da escola em um ambiente livre de qualquer discriminação tem crescido e ganhado adesão de instâncias federais e estaduais. Em decorrência disso, é crescente também o ingresso de alunos com necessidades especiais no Ensino Superior. As exigências das leis sobre acessibilidade nesse nível de ensino constam da portaria no 1.679 , de 2 de dezembro de 1999, assinada pelo ministro Paulo Renato Souza, que considera o disposto na Lei no 9.131, de 24 de novembro de 1995, na Lei no 9.394, de 20 de dezembro de 1996, e no Decreto no 2.306, de 19 de agosto de 1997, e, também, a necessidade de assegurar aos portadores de deficiência física e sensorial condiçóes básicas de acesso ao Ensino Superior, de mobilidade e de utilização de equipamentos e instalaçóes das instituições de ensino.

Além da preocupação com o acesso, o Ministério da Educação demonstrou, em documento oficial, intitulado $O$ acesso de alunos com deficiência às escolas e classes comuns da rede regular (Ministério Público Federal; Fundação Procurador Pedro Jorge de Melo e Silva, 2004), preocupação com a permanência escolar dos alunos com necessidades educacionais especiais, uma vez que - pela falta de apoio tecnológico e pedagógico - muitos pensam em desistir. $\mathrm{O}$ documento tinha a finalidade de efetivar uma política nacional de educação inclusiva, fundamentada na ideia de uma sociedade que reconhece e valoriza as diferenças, e trazia um referencial para a construção de sistemas educacionais inclusivos que atendessem às peculiaridades de todos os cidadãos.

Em 2007, o Instituto Nacional de Estudos e Pesquisas Educacionais Anísio Teixeira (INEP) concluiu que $0,15 \%$ do total de alunos do Ensino Superior é de pessoas com deficiência, o que corresponde a 10 mil pessoas. Os estudantes com deficiência visual, de acordo com o mesmo levantamento, representavam 32\% desse número, ficando atrás apenas dos deficientes físicos, que somavam 38\%. Desse modo, as universidades precisam estar cada vez mais preparadas para cumprirem aquilo que prevê a legislação.

Para os alunos não videntes, a portaria no $1.679 / 99$ exige um compromisso formal da instituição de proporcionar sala de apoio, caso seja necessário, do início ao término do curso. A sala deve conter uma máquina de datilografia Braille, impressora Braille acoplada a computador, sistema de síntese de voz, gravador, fotocopiadora que amplie textos, plano de aquisição gradual de acervo bibliográfico em fitas de áudio, software de ampliação de tela, equipamento para ampliação de textos para atendimento a aluno com visão subnormal, lupas, réguas de leitura, scanner 
acoplado a computador e plano de aquisição gradual de acervo bibliográfico dos conteúdos básicos em Braille. Contudo a lei não ordena que haja capacitação dos docentes nem orienta por onde as instituiçôes devem iniciar o trabalho de inclusão.

O Ministério da Educação auxilia com algumas explicaçōes, como por meio do documento citado sobre o acesso de alunos com deficiência, porém não são suficientes diante da dimensão dos entraves encontrados por profissionais de ensino não especializados no atendimento de pessoas com determinadas necessidades especiais quando elas passam a frequentar suas aulas.

$\mathrm{Na}$ tentativa de solucionar o problema vivenciado por um professor de Linguística diante das necessidades especiais de uma acadêmica cega, foi desenvolvida uma pesquisa cuja finalidade inicial era vislumbrar a melhor maneira de produzir/ adaptar um material didático de fonética e fonologia que possibilitasse, inclusive, mostrar os símbolos aos alunos não videntes, partindo da hipótese inicial de que o relevo seria o melhor recurso para a adaptação. Assim, objetiva-se, neste artigo, demonstrar o processo de produção/adaptação do material didático de fonética e fonologia, por meio da descrição das etapas da pesquisa, desde suas dificuldades fomentadoras até a apresentação das adaptaçôes feitas no material didático escolhido.

\section{AS DIFICULDADES FOMENTADORAS DA PESQUISA}

A pesquisa surgiu devido a uma lacuna encontrada durante a formação de uma acadêmica deficiente visual no curso de licenciatura em Letras da Universidade Estadual de Maringá (UEM). No segundo ano da graduação de Letras, licenciatura em Português, os discentes cursam a disciplina Linguística II, em que estudam os níveis de estruturação interna da língua portuguesa e observa-se a organização sistemática de seus elementos, com o intuito de desenvolver nos futuros profissionais habilidades que, posteriormente, os auxiliem em sala de aula como professores. Nesse âmbito, faz-se necessário o estudo de fonética e fonologia, ramos do conhecimento linguístico que apresentam, respectivamente, "os métodos para a descrição, classificação e transcrição dos sons da fala” (Silva, 2002, p. 23) e dos fonemas da língua.

O conteúdo relativo ao estudo de fonética e fonologia na disciplina engloba, além da explicitação teórica e metodológica dessas duas áreas, a descrição do aparelho fonador e sua funcionalidade na produção dos sons, o estudo dos sons da fala e dos sons da língua, as noçóes de alofone, fonema, arquifonema, traços distintivos e sílaba. Também contempla práticas de análise fonética e fonológica e trabalhos de aplicação dos conteúdos à futura prática profissional dos discentes. 
A entrada da discente com necessidades educacionais especiais requereu do professor da disciplina uma mudança de atitude em relação ao curso que realizava anteriormente em suas aulas. De modo geral, a deficiência da aluna obrigou-o a conferir a ela uma atenção diferenciada dos demais alunos, que abrangia desde um constante endereçamento do olhar em sua direção e aproximação física, mais do que seria natural com alunos sem necessidades especiais, com o objetivo de verificar se ela apresentava algum tipo de dificuldade no acompanhamento das discussóes, até eliminação, na fala do professor, do uso de dêiticos mostrativos e locativos que indicavam lugares na lousa, no corpo e na sala de aula.

É importante ressaltar que, seguindo as orientações governamentais, a UEM desenvolveu o Programa Multidisciplinar de Pesquisa e Apoio à Pessoa com Deficiência e Necessidades Educativas Especiais (PROPAE), que se responsabiliza pela adaptaçáo para o código Braille, por meio do programa de computador Braille Fácil 3.5a, dos textos utilizados em sala de aula pelos professores. No entanto, quando o material de Linguística foi levado ao PROPAE, a responsável informou que não havia como traduzir os símbolos fonéticos e fonológicos nem as figuras. Assim, o material da discente ficou lacunar, obrigando o professor a tomar outras medidas para tentar sanar os problemas encontrados.

No que diz respeito especificamente ao conteúdo, a discente não tinha como acompanhar os vídeos apresentados na disciplina, entre eles os que mostravam o funcionamento da glote e das cordas vocais. Entretanto, esse problema foi parcialmente resolvido com os exercícios de reflexão sobre o funcionamento do aparelho fonador no próprio corpo, como colocar os dedos no pescoço sobre a regiāo da laringe para sentir a vibração ou não das cordas vocais, e perceber o posicionamento da língua em diferentes partes da cavidade bucal para a produção dos sons.

Todos os exercícios que envolviam transcriçâo fonética e fonológica não foram realizados pela discente, em razão da ausência de meios para representar os símbolos, criando obstáculos em sua formação, entre eles: dificuldade para entender as diferenças entre as transcrições fonéticas e fonológicas; diferença entre fonética e fonologia e entre sons e fonemas. Logo, tudo o que dizia respeito à transcrição ficou deficitário em sua formação.

A ausência de símbolos no material da discente também obrigou o professor a repetir a classificação de um som ou fonema toda vez que aparecia; por exemplo, quando o [t] estava grafado no texto, o professor dizia "africada alveolopalatal desvozeada", o que causou certa irritaçâo nos demais alunos depois que haviam sistematizado os símbolos. A ausência de formas de representar os símbolos também 
levou à produção de avaliaçóes para a discente não vidente parcialmente diferentes daquelas de seus colegas de sala.

A favor da inclusão educacional e da equiparação de oportunidades entre alunos videntes e não videntes, iniciou-se a investigação de qual seria o recurso didático mais eficaz para cumprir o objetivo inicial da pesquisa de representar os símbolos fonéticos e fonológicos aos alunos cegos.

\section{A ESCOLHA DO MATERIAL}

O primeiro passo da pesquisa foi escolher o material didático que serviria de base para o trabalho. A seleçáo passou, primeiramente, por textos presentes na bibliografia da disciplina, restringindo a uma análise mais pormenorizada - por serem diretamente utilizados nas aulas - os seguintes: Fonética e fonologia do português (Silva, 2002); Iniciação à fonética e fonologia (Callou e Leite, 1993); Estrutura da língua portuguesa (Câmara Jr., 1976); Fonética e fonologia (Antonio e Benites, 2011). Depois, a seleção foi estabelecida considerando a maior vinculação da proposta à formaçáo de professores e à acessibilidade do material.

A Resolução CNE/CP n. 1, de 18 de fevereiro de 2002, que determina as Diretrizes Curriculares Nacionais para a Formação de Professores da Educação Básica, e o Parecer CNE/CP 9/2001 estabelecem princípios norteadores para a formação de professores. O princípio norteador referente à prática pedagógica e às questôes a ela relacionadas ganha destaque nesses documentos oficiais, que, mais marcadamente o Parecer, assinalam a necessidade de o futuro professor dominar os conteúdos básicos das áreas de conhecimento que serão objeto de sua atividade docente.

Dos materiais analisados, enquadra-se diretamente numa proposta de formação de professores o livro organizado por Antonio e Benites (2011). Verifica-se na apresentação do livro a menção direta ao atendimento das determinações do CNE/ CP 9/2001. Para os organizadores, cada disciplina deve explicar: 1) os conteúdos a serem ensinados dentro do enfoque epistemológico adotado; 2) a metodologia a ser empregada na abordagem dos conteúdos. Assim,

No que tange ao estudo dos sons vocais, importa selecionar conteúdos relevantes para prática docente, particularmente no enfrentamento de questôes relacionadas a aspectos da variação linguística, à interferência da fala na escrita e à abordagem de gêneros textuais em que a expressividade 
fônica tenha um papel relevante. (Antonio e Benites, 2011, p. 11-12).

O livro está organizado em cinco capítulos, os dois primeiros voltados para uma abordagem de questôes gerais sobre fonética e fonologia e os três outros para questôes de aplicação prática dessas disciplinas à variação linguística, à escrita e à expressividade fônica em gêneros textuais, buscando, assim, eliminar, segundo os organizadores, "uma ideia simplista, mas muito difundida, de que a fonética e a fonologia seriam disciplinas áridas, pouco úteis ao egresso do curso de Letras" (Antonio e Benites, 2011, p. 12). Portanto, o livro atende às solicitaçóes dos documentos oficiais sobre as necessidades de um curso de licenciatura apontadas anteriormente, e, pela forma como foi organizado, não prevê a necessidade de conhecimentos prévios para sua compreensão, pois, em todo o material, mas especialmente nos capítulos teóricos, são propostos numerosos exercícios destinados à fixação e à aplicação da teoria.

Quanto à acessibilidade do material, o livro faz parte de uma coleção voltada a alunos de licenciatura, vinculada à Universidade Aberta do Brasil (UAB). Destinado primeiramente aos discentes do curso de educação a distância, esse material didático passou a ser utilizado também nos presenciais. Por ser um livro financiado pela Coordenação de Aperfeiçoamento de Pessoal do Ensino Superior (CAPES), fica disponível na plataforma da UAB, o que pesou em sua escolha, pois se os resultados da pesquisa fossem positivos, outros cursos poderiam ter acesso ao material.

Em sua composição textual, os capítulos do livro apresentam não só os símbolos fonéticos e fonológicos, como também figuras e quadros. Os pesquisadores partiram da hipótese inicial de que o relevo seria o melhor recurso para produzir/ adaptar os símbolos e, por extensão, as figuras e quadros, baseando-se em reportagens e outros programas televisivos que mostravam produçóes em relevo para deficientes visuais e, também, em um levantamento bibliográfico primário sobre esse assunto. No entanto, cientes de que ainda náo tinham subsídios consistentes para levar adiante o objetivo traçado, iniciaram o segundo momento da pesquisa: as entrevistas com profissionais especializados e mais experientes em educação de deficientes visuais. 


\section{AS ENTREVISTAS COM PROFISSIONAIS DA EDUCAÇÃO ESPECIAL}

O paradigma da pesquisa foi o qualitativo-interpretativista, pois partiu da interpretação de experiências vividas por profissionais da educação especial com alunos deficientes visuais e considerou variáveis que vão além de uma simples relação de causa e efeito. Como metodologia de coleta de dados, escolheu-se a entrevista semiestruturada que, segundo Triviños (2012), é um dos principais meios que possui um investigador em uma pesquisa qualitativa, uma vez que, além de valorizar sua presença, permite a espontaneidade por parte do informante, o que enriquece muito o processo de investigação.

A entrevista semiestruturada parte de alguns questionamentos básicos, porém não se prende a eles, já que vão surgindo outras perguntas à medida que são obtidas as respostas do informante. Este segue suas experiências dentro do foco estabelecido pelo pesquisador e, desse modo, participa da elaboração do conteúdo da pesquisa. A entrevista constitui-se como um processo de interação social, no qual informante e pesquisador trocam os turnos de fala.

Nesse sentido, durante os estudos acerca da entrevista semiestruturada, observou-se que o objetivo de "verificar" deveria ser substituído pelo de "vislumbrar”, conforme assinala Manzini (2004), já que a entrevista fornece relatos, não fatos. O termo "verificar", segundo o autor, está relacionado a fatos, portanto não se aplica a entrevistas.

O primeiro passo foi organizar o roteiro de questionamentos básicos, algo que poderia ser feito de duas maneiras: por meio de perguntas ou de tópicos. Optou-se pelas perguntas, pois elas permitem que o pesquisador formule adequadamente as indagaçóes no momento da entrevista.

As perguntas foram resultado de toda informação recolhida sobre o fenômeno social interessado - a ausência de representações dos símbolos fonéticos e fonológicos para os deficientes visuais - e organizadas em três eixos temáticos: o primeiro constituiu-se de três questóes que buscavam conhecer os informantes, bem como a formação de cada um e o que viam como facilidade e como dificuldade no trabalho com os não videntes; o segundo, composto por seis questóes, aparelhou a investigação acerca dos recursos já utilizados pelos informantes, o que incluiu perguntas sobre o Braille e suas limitaçóes; o terceiro e último, por sua vez, almejou, por meio de duas questóes, saber qual seria o recurso mais eficaz no processo de ensino e aprendizagem de cegos quando o Braille é insatisfatório, e como tal recurso seria aplicado para a representação dos símbolos fonéticos e fonológicos. 
Elaborado o roteiro de perguntas, o segundo passo foi procurar os informantes. Na cidade de Maringá-PR, onde ocorreu a pesquisa, há em algumas escolas públicas os chamados Centros de Atendimento Especializado para Deficientes Visuais (CAEDVs), onde crianças e adolescentes são atendidos por profissionais especializados em deficiência visual. Lá, eles recebem o apoio necessário para o desenvolvimento de suas habilidades táteis e o auxílio em suas tarefas diárias do ensino regular, ou mesmo do Ensino Superior, no caso de alguns. Além desses centros, existe também o Centro de Apoio Pedagógico (CAP), onde são produzidos materiais didáticos diversos para os deficientes visuais da cidade e de outros 119 municípios do estado do Paraná. Assim, procuraram-se os CAEDV s e o CAP, a fim de localizar profissionais da educação especial que pudessem conceder a entrevista ou mesmo contribuir diretamente com a pesquisa.

Visitaram-se dois CAEDVs, situados em duas escolas públicas - que serão tratadas por escola I e escola II -, e o CAP, que também funciona em uma escola pública no centro da cidade de Maringá, que será referida como escola III. Houve a contribuição de cinco profissionais: um da escola I, mencionado como informante I, dois da escola II, mencionados como informante II e informante III, e outros dois da escola III, o informante IV e o informante V.

$\mathrm{O}$ contato com esses profissionais ocorreu numa primeira ida às escolas, quando a pesquisa foi apresentada a eles e lhes foi entregue uma carta de esclarecimento, acompanhada de um "termo de aceite de participação em pesquisa", que assegurou o uso das informaçóes a serem obtidas nas entrevistas para a finalidade da pesquisa em questão, assim como o sigilo da identidade dos informantes em futuras publicações. A partir da aceitação dos informantes e dos termos devidamente assinados, foram marcadas as entrevistas, que ocorreram entre os dias $20 \mathrm{e}$ 27 de agosto de 2014 .

Conforme citado, foram cinco informantes: o I trabalha com deficientes visuais há nove anos e tem especialização na área de educação especial, com ênfase em deficiência visual (DV) e deficiência auditiva (DA); o informante II trabalha com esse público há catorze anos e tem especialização e Programa de Desenvolvimento Educacional (PDE) em educação especial; o III é deficiente visual, trabalha com deficientes visuais há aproximadamente dezesseis anos e tem especialização em educação especial e neuropedagogia; o informante IV trabalha com tal população há dezoito anos e tem especialização em língua portuguesa e em educação especial; o V trabalha com deficientes visuais há 24 anos, tem especialização em língua portuguesa e nas diversas áreas da deficiência e mestrado em psicologia. É válido dizer que os informantes IV e V foram, a pedido deles, entrevistados simultaneamente 
e, nesta entrevista, contou-se com algumas contribuiçóes de um sexto informante, que é deficiente visual e trabalha na produção de materiais do CAP. Essa descrição permite verificar o elevado grau de conhecimento científico e de prática dos profissionais entrevistados, o que foi fundamental para o desenvolvimento da pesquisa.

As entrevistas foram gravadas pela câmera de um notebook e transcritas imediatamente após sua realização, como idealiza Triviños (2012). Optou-se pela gravação ao invés de anotaçóes, porque os áudios e vídeos permitem o acesso a todo o conteúdo apresentado pelos informantes em momentos posteriores à entrevista, garantindo análise mais precisa dos dados. Inicialmente, a presença da câmera inibiu um pouco os informantes, mas logo esqueceram o equipamento e agiram espontaneamente, desenvolvendo os assuntos levantados nas perguntas.

A primeira visita às escolas I, II e III, em que se buscou o aceite por parte dos profissionais em participar da pesquisa, permitiu, além da apresentação do projeto, a familiarização entre investigador e informantes, o que propiciou, no momento das entrevistas, um clima amistoso. O tempo de duração das entrevistas foi inferior a trinta minutos, pois, de acordo com Triviños (2012), as que se prolongam mais do que isso se tornam repetitivas e consideravelmente pobres.

O início de cada entrevista foi marcado por incertezas tanto por parte do investigador quanto do informante, contudo a confiança estabelecida entre ambos permitiu que se cumprissem os objetivos e se chegasse aos resultados discutidos a seguir.

\subsection{A discussão dos dados das entrevistas}

Quando questionados sobre as dificuldades encontradas no trabalho com os deficientes visuais, os informantes I, IV e $\mathrm{V}$ responderam que a maior está relacionada à adaptação de material, seja pela falta de tempo para isso - de modo que o aluno cego consiga acompanhar os demais em sala de aula-, seja pelos limites do Braille, como asseveraram os informantes IV e V. Segundo eles, por vezes a linguagem Braille não é capaz de representar determinados conteúdos, como os símbolos fonéticos e fonológicos, por exemplo. Nesse sentido, o informante $\mathrm{V}$ revela que "quando isso aparece para a gente, realmente é um entrave, porque nós não temos como representar isso para o aluno” (Entrevista 4).

Ao admitirem ser o Braille um recurso limitado em determinados contextos, os informantes foram questionados sobre quais materiais utilizavam em tais casos, pergunta que visava a melhor discussão sobre a adaptaçáo do material que seria desenvolvido com a pesquisa. Os informantes I, II e IV, então, listaram uma série 
de materiais, todos eles formas de relevo, como se pode verificar pela fala do I: "muita colagem com canudinho, botão, arroz, feijão, milho, porque a gente tem que variar muito" (Entrevista 1), e do informante IV: "Linha, barbante, papel com textura, tecidos [...] Miçanga, botáo" (Entrevista 4).

Os três informantes deixaram explícita a ideia de que o trabalho artesanal em relevo é a alternativa quando o Braille se torna um recurso incapaz de demonstrar determinado conteúdo ao aluno. Nesse sentido, o papel dos CAEDV e do CAP é fundamental, visto que o professor, em sala de aula, não possui tempo hábil para produzir tais materiais e os Centros é que são incumbidos de fazê-lo. Quando a demanda é muito alta por parte dos professores do ensino regular, os Centros contam, ainda, com o apoio dos detentos da Penitenciária Estadual de Maringá (PEN), por um programa chamado "Visão de Liberdade", em que eles produzem os materiais em relevo para os deficientes visuais e, por meio desse trabalho, conseguem remissão de pena.

Quando questionado se existe uma forma de relevo mais eficaz do que a outra, o informante IV afirmou que o que se deve buscar é a padronizaçáo, de maneira que o cego, ao sentir determinada textura, reconheça-a sempre como representação de determinado conteúdo:

Vamos pensar, a gente está fazendo junto com a penitenciária, a gente pretende fazer uma série de mapas, o que a gente está tentando, todos os contornos, seja do Mapa Múndi, do Brasil ou das Américas, a gente usa o mesmo material. Entáo quando o aluno cego tocar aqueles diversos mapas, ele encontrou aquele material, ele sabe que aquele material é o contorno de um mapa. Até aquela representaçẫo na Matemática, gráficos de função x e y, então sempre que eu for fazer gráfico de função, eu vou usar a mesma linha, o mesmo material, então o cego botou a mão ali, ele já sabe que aquilo é uma representação (Entrevista 4).

A padronização é, portanto, algo que facilita a identificação dos conteúdos por parte do aluno deficiente visual. Quanto a isso, é importante lembrar também que, segundo o informante III, quem produz material em relevo deve preocupar com o tipo de material a ser utilizado - este deve ter uma textura agradável ao tato, de modo a não machucar as máos de quem o toca, inclusive porque o aluno cego irá tocá-lo várias vezes para compreender o que ele representa. 
No entanto, apesar de os materiais em relevo serem muito solicitados, ainda o informante III, que é deficiente visual, afirmou não gostar do relevo:

Eu não sou muito a favor de relevo. Eu tenho deficiência visual e eu acho muito difícil você discriminar o material em alto relevo. Aí dependeria muito do professor que vai atender esse aluno, para ele oferecer recursos antes de estar trabalhando esse relevo, para esse aluno conseguir compreender o relevo. [...] Tem que ter um trabalho antes, porque o relevo - às vezes você tem lá um livro, uma literatura, eu tenho o desenho de uma borboleta, eu tenho uma noçáo do que é uma borboleta porque eu já enxerguei, mas o cego que nasceu cego, que teve a cegueira congênita, ele não vai ter essa informação, então ele não faz essa formação do desenho, para ele é muito difícil. [...] A gente perde muito essa compreensão do formato. Às vezes eu pego um livro lá, tem um desenho de uma casa. Para você aquilo lá é uma casa, mas para mim - que já perdi essa questão da parte visual - então eu não consigo identificar com a mesma exatidão que você. Então tem que tomar um cuidado muito grande quando se for trabalhar com relevo (Entrevista 3).

$\mathrm{Na}$ mesma direção, o informante VI, que trabalha no CAP e também é deficiente visual, afirmou:

O desenho, uma dificuldade que eu tenho, na minha opiniáo, e outras pessoas têm também, pessoas cegas, é que muitos de nós não fomos trabalhados com isso na infância, lá atrás, com cinco, seis, sete anos, porque você percebe a diferença dos cegos de outros lugares, de outros estados, que tiveram esse trabalho feito desde o início para outros cegos, mesmo eu que nasci cego, meu irmão também, mas que não teve esse trabalho feito. Porque o desenho, você que enxerga, você olha e vê o todo. O cego, ele tem que tocar e com as mãos estar sentindo esse todo depois, posteriormente, e essas linhas, o que acontece, eu acredito que o desenho ele é funcional, é útil, sim, desde que a pessoa cega tenha alguém do lado explicando para ela o que é que está ali (Entrevista 4).

Vale ressaltar, também, a fala do informante $\mathrm{V}$, ainda a respeito do relevo:

E aí se eu for representar, vamos pensar na catedral que o informante VI citou, às vezes eu vou representar essa

Romualdo, E.C.; Marques, G.S. O processo de produção/adaptação de material didático... 
maquete em relevo, entâo eu vou representar uma figura tridimensional numa figura plana. Eu, às vezes, vou utilizar vários materiais a mais, porque visualmente eu olho, eu vejo uma foto. Agora, em relevo, você tem que utilizar vários materiais e, às vezes, o cego não consegue perceber que era uma figura tridimeznsional que ali está representada com materiais diferentes, entáo é complexo. E, às vezes, a gente vê muito situaçóes assim, você olha o material, ele está muito bonito, mas não está funcional para a pessoa cega. Então isso é bastante complexo mesmo, às vezes a gente tem muitas pessoas que falam: "Olha que bonito que ficou", principalmente, às vezes, envolvendo pesquisa: "Olha, eu fiz esse material para cegos", e você olha e fala: "Ah, que bonito, mas não é funcional". Então a gente tem que ter essa noção, tem que ser bonito, não é porque é para cego que o material tem que ser feio, mas que ele seja bonito e funcional (Entrevista 4).

Como observa-se pelas entrevistas, segundo os informantes não videntes, o relevo é um recurso que requer um mediador sempre ao lado do aluno cego, porque este pode ou não ter suas habilidades táteis desenvolvidas e, ainda que as tenha, seu contato com o relevo vai da parte para o todo, ao contrário do que acontece com os videntes, que visualizam o todo e depois se ocupam em compreender as partes. Há, nesse sentido, duas dificuldades em se trabalhar com o relevo: a) a ausência de tempo hábil do professor em sala de aula, que não tem a possibilidade de atuar exclusivamente como mediador do aluno cego; b) a dificuldade, por parte do aluno não vidente, em compreender o que está sendo demonstrado pelo relevo, por precisar tocar parte por parte e, somente a partir disso, tentar "imaginar" como seria o todo, tanto os que nasceram cegos, quanto os que perderam a visão, pois, segundo o informante III, o indivíduo vai perdendo a noção de como são, de fato, as coisas com o passar do tempo.

A participação dos informantes deficientes visuais foi crucial no processo de investigação, por fazer os pesquisadores repensarem a hipótese de que a melhor maneira de representar os símbolos fonéticos e fonológicos para os não videntes seria alguma forma de relevo. A esse importante fator, somaram-se outros dois: o apresentado pelo informante $\mathrm{V}$, ao relatar que a produção de material para deficientes visuais em relevo é difícil, porque o material precisa ter funcionalidade, de modo que considere as dificuldades dos cegos em reconhecer o que está ali representado e, assim, traga diversas texturas; também o fato de todos os informantes terem respondido que o Braille é o recurso mais eficaz no processo de ensino e 
aprendizagem de cegos, apesar dos aspectos negativos, como a questáo do volume dos materiais em Braille e o tempo que demoram para serem produzidos, o que se pode verificar pela fala do informante I:

A maior dificuldade nossa são os alunos que estáo em faculdade. Tem uma aluna que terminou Pedagogia, já passou no concurso, é professora da prefeitura, cega, com 40 horas de concurso. E agora tem outra, que é de Letras. Qual é o maior problema? Vem os materiais em Braille para ela, só que enquanto a turma tinha o livro, aquelas apostilas tiradas xerox no quiosque, tudo à tinta, para fazer naquele dia, naquela aula de Literatura, daquela matéria, o nosso aluno cego tem que esperar e chega um mês depois, por exemplo, porque ou é o CAP que bate ou é o PROPAE que tem dentro da UEM, que dá esse apoio também. Então, o material fica sempre para depois. Quando a turma está vendo - porque é muito material, são livros, são contos, são textos, são aqueles teóricos da Pedagogia, são textos extensos, que não tem como a gente bater aqui numa tarde, por exemplo - ela chega hoje e não dá para levar amanhã, nem para a semana que vem não dá, porque são materiais de bastante volume, então esse é o problema (Entrevista 1).

A importância do Braille também se evidenciou pela fala do informante II, quando questionado se o considera o recurso mais eficaz no processo de ensino e aprendizagem de cegos. Para ele, é importante o aluno não vidente ter contato físico com aquilo que lê:

Ah, até agora, para a leitura usando o tato, sem usar outros recursos, por exemplo auditivos, é, ainda é. E acho que o mundo inteiro considera ainda. Se bem que já tem os livros falados, mas eu acho que o gosto da leitura, da pessoa mesmo ir decodificando, eu percebo que eles não gostam muito, porque é cansativo... E ouvindo, só que ouvindo também chega uma hora que cansa, entâo eles precisam também, porque não é em todo lugar que eles vão ter tudo falado para eles, livro falado, as coisas faladas. Em algum momento eles vão ter que registrar, tem que registrar e tem que ler também (Entrevista 2).

A fala do informante $V$ levou a investigação para o mesmo caminho apontado pelo informante II:

Romualdo, E.C.; Marques, G.S. O processo de produção/adaptação de material didático... 
A gente tem aí uma tendência, uma discussão grande da "desbraillização", que a gente tem ouvido falar, até com a proposta de material do MEC, que é o Mecdaisy, que o aluno cego passaria a ouvir os conteúdos no computador, mas enquanto professores, principalmente professores de Língua Portuguesa, nós acreditamos que o aluno tenha que ler esse material, ele tenha que conhecer esse código em Braille, essa codificação toda, então é imprescindível a utilização. Eu digo assim, que o Braille foi inventado, e Louis Braille com certeza teve uma iluminação para fazer isso, até Louis Braille a gente não tinha um sistema dessa forma, entáo por mais tecnologia, mais avanço tecnológico que a gente tenha tido, a gente não tem nada que ainda superasse o Braille. Eu sempre comparo com os alunos, da mesma forma que nós ainda recorremos - com toda tecnologia e às vezes com mais condiçôes que os deficientes visuais, que algumas coisas às vezes eles ainda náo conseguem ter acesso - por mais que a gente tenha disponibilizado esses textos no computador, a gente precisa do livretinho, a gente escreve ainda, então é mais ou menos assim (Entrevista 4).

O ponto de vista dos informantes II e $\mathrm{V}$ é condizente, também, com o que afirma Baptista (2000). Na perspectiva do autor, os livros sonoros e a informática são importantes para o desenvolvimento cultural dos cegos, mas nada poderá ou deverá substituir o Braille como sistema base da sua educação. Segundo ele, bem como a leitura visual, "a leitura em Braille leva os conhecimentos ao espírito através de mecanismos que facilitam a meditação e assimilação pessoal daquilo que se lê" (Baptista, 2000, p. 8). Esse sistema permite estudar os quadros em relevo e ler eficientemente os livros técnicos, e é, ainda, o único meio de leitura disponível para os surdos cegos. Ademais, o autor assinala que o aperfeiçoamento da escrita está relacionado com a leitura Braille que cada um faz, como acontece com os videntes, pois é por meio da leitura que se entra em contato com a estrutura e a microestrutura dos textos.

Após considerar todos esses fatores importantes, antes desconhecidos, que vieram à tona no momento das entrevistas, vislumbrou-se que a melhor forma de representar os símbolos fonéticos e fonológicos seria o Braille, abandonando a hipótese inicial da pesquisa, que tinha o relevo como principal alternativa. Contudo, até então, não havia celas (os seis pontos que formam uma unidade Braille) para fazê-lo, tampouco se sabia da existência de celas Braille disponíveis 
para representarem novos conteúdos, o que se descobriu ao final da entrevista realizada com os informantes IV e V, no CAP de Maringá.

Segundo eles, as ciências exatas - Matemática, Química e Física - sofriam pela mesma problemática que suscitou a pesquisa em foco: a ausência de representação para seus símbolos. A necessidade de levá-los ao aluno deficiente visual resultou no surgimento dos códigos matemático, químico e físico, unificados e acessíveis aos profissionais que produzem materiais para cegos, de modo que todos a serem produzidos a partir daí trouxessem aqueles símbolos adaptados e, dessa forma, o aluno não vidente pudesse aprendê-los, bem como o alfabeto, por exemplo.

Os informantes IV e V, que trabalham com a produção de diversos materiais para deficientes visuais há anos, propuseram a adaptação do material sobre fonética e fonologia para o Braille, inclusive dos símbolos. Depois do estudo das entrevistas, os pesquisadores concluíram que o Braille satisfazia todas as exigências para um bom material destinado a deficientes visuais, pois:

1) permite a autonomia por parte do aluno deficiente visual;

2) diferentemente de outras formas de relevo, não requer grande exercício de abstração do aluno deficiente visual;

3) é agradável ao tato;

4) pode ser reproduzido pelas impressoras Braille, capazes de converter todo tipo de texto eletrônico para o Braille, o que garante a padronização e a produção em massa.

Após consultados, os demais informantes, I, II e III, concordaram com a proposta, visto que também apontaram ser o Braille o recurso mais eficaz no processo de ensino e aprendizagem de cegos, também porque - além das quatro razóes supracitadas - a escolha de outro recurso didático poderia apresentar dificuldades de aplicação durante ausência de materiais indispensáveis para sua produção. Assim, iniciou-se o trabalho de adaptação pelos informantes IV e V, profissionais do CAP.

Inicialmente, quando se tinha em mente alguma forma de relevo que não fosse o Braille, por exemplo, o uso de barbante formando as imagens dos símbolos, pensava-se que a produção poderia ser feita pelos investigadores. No entanto a adaptação de livros para transcriçôes em Braille pode acarretar a perda de fidelidade quanto ao conteúdo original, por isso é necessário que o trabalho seja feito por pessoas realmente especializadas na educação de deficientes visuais. Os pesquisadores, então, acompanharam a adaptação, requerendo que os símbolos, 
quando possível, mantivessem relaçóes entre si e atendessem às especificidades das transcrições fonéticas e fonológicas.

\section{A DESCRIÇÃO DO MATERIAL ADAPTADO}

Primeiramente, antes de tratar das adaptaçóes no conteúdo de fonética e fonologia, é importante colocar que o livro adaptado para linguagem Braille é mais volumoso que o livro em tinta, uma vez que uma página em tinta corresponde a, mais ou menos, três páginas em Braille, e o material original traz muitos quadros, os quais requisitaram algumas quebras de página e conferiram maior volume - as 108 páginas do livro em tinta resultaram em 326 páginas em Braille. Por isso, as profissionais do CAP organizaram o material adaptado em duas apostilas: a primeira traz a capa, seguida dos símbolos adaptados, da folha de rosto, do sumário, da apresentaçẫo dos autores, da coleção e do livro, e os três primeiros capítulos (178 páginas); na segunda, portanto, apresentam-se o quarto e quinto capítulos (148 páginas).

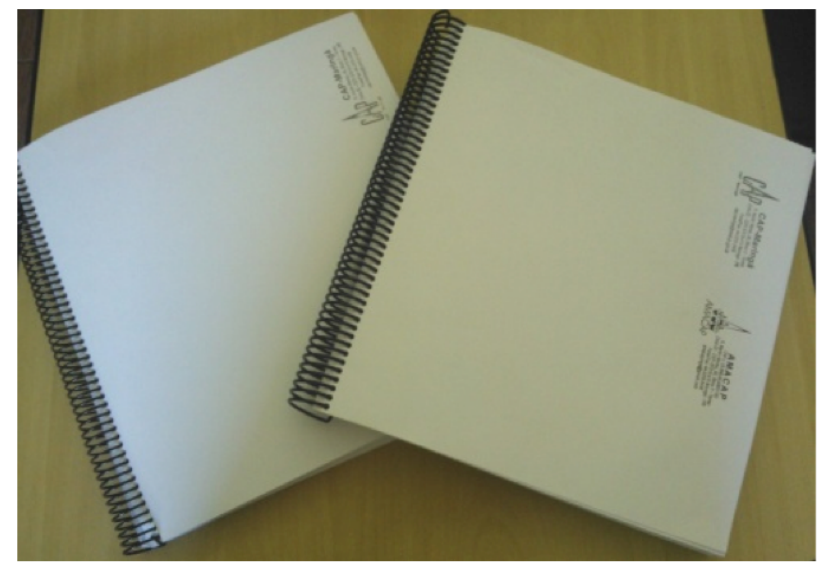

Figura 1 - Livro em Braille dividido em duas apostilas Fonte: Elaborado pelos autores

As capas do livro em Braille e em tinta são idênticas no que concerne à linguagem verbal, no entanto a imagem apresentada na capa do livro em tinta náo consta na versão adaptada, bem como outros aspectos que são, na verdade, recursos visuais, como a página de guarda do livro, por exemplo, com o título "Fonética e Fonologia” centralizado. O livro em Braille não apresenta essa diagramação, pois o título já é apresentado na capa. O conteúdo do verso da página de guarda, que 
traz os nomes dos membros do conselho editorial e da equipe técnica da obra, aparece normalmente na versão adaptada, mas fica sendo "frente", em vez de verso.

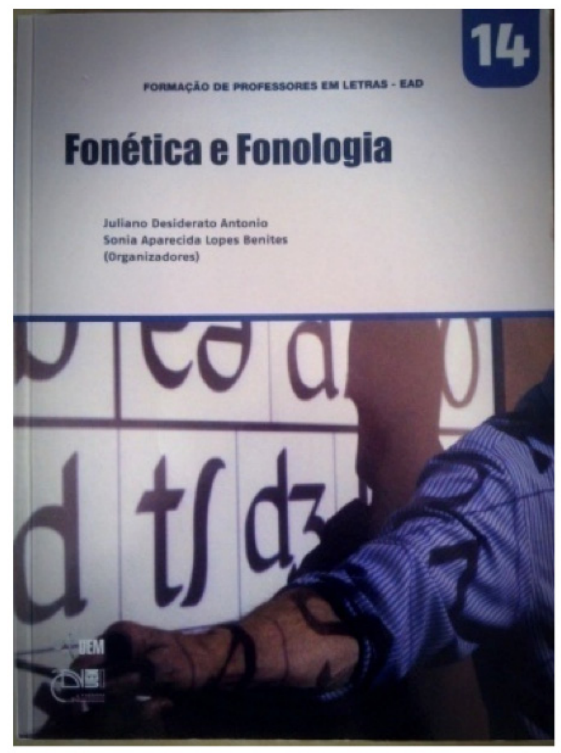

Figura 2 - Capa do livro Fonética e fonologia

Fonte: Antonio e Benites (2011).

Em seguida à página com a lista de membros do conselho editorial e da equipe técnica, o livro em Braille - assim como o em tinta - apresenta uma folha de rosto, cujo verso traz os nomes de quem deu apoio técnico, de quem colocou o material nas normas, catalogou, e de quem editou e produziu o editorial e a capa. Traz, ainda, o endereço para correspondência com a editora do livro e os dados internacionais de catalogação da publicação.

Antes mesmo do sumário, a versão adaptada apresenta os símbolos fonéticos e fonológicos que serão utilizados no decorrer do material, em sua devida forma adaptada, antecipando o contato do aluno não vidente com os símbolos que serão encontrados no material. Só depois é que se tem o índice de condução do livro, com o título do assunto a ser tratado e a paginação correspondente. No mais, a versão em Braille segue a mesma ordem da em tinta, com a seção "Sobre os autores", seguida da apresentação da coleção e da apresentação do livro, tudo isso transposto exatamente da forma como está em tinta. 
O material original está dividido em cinco capítulos, dentre os quais, como já mostrado, dois tratam de questôes teóricas gerais acerca de fonética e fonologia, e os outros três abordam questôes de aplicação prática dessas disciplinas. A linguagem verbal foi transposta para o Braille, na versão adaptada, sem o menor problema. No entanto o livro em tinta utiliza-se também da linguagem não verbal, o que provocou alguns entraves na adaptação.

No primeiro capítulo, há a visão anatômica de uma hemiface, com a representaçáo dos articuladores - lábios, dentes, alvéolos, palato duro, véu palatino, úvula e língua - que são partes do trato vocal utilizadas na produção dos sons, como se pode observar na figura seguinte:

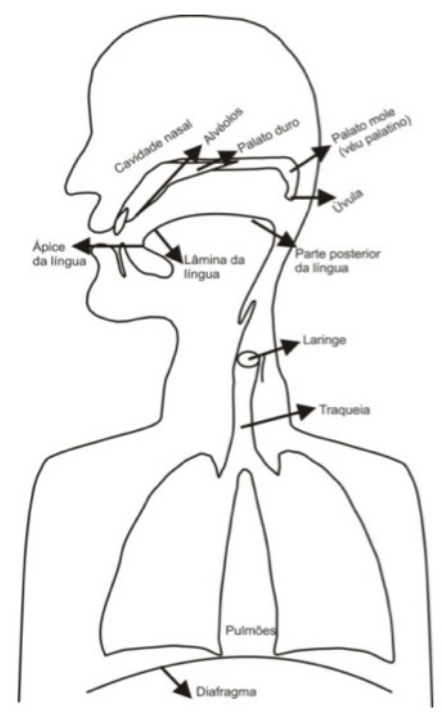

Figura 3 - Aparelho fonador

Fonte: Antonio e Benites (2011, p. 16)

Além deste desenho, há também outras duas gravuras que mostram o processo de abertura e fechamento da glote, o que implica a produção de sons ora desvozeados, ora vozeados, conforme as figuras que seguem: 

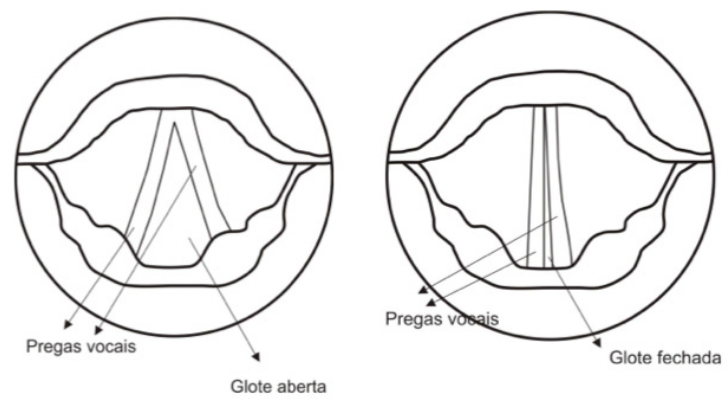

Figura 4 - Estados da glote

Fonte: Antonio e Benites (2011, p. 17)

Antes das entrevistas com os profissionais especializados, acreditava-se que a melhor forma de representar essas figuras seria o relevo, mas a contribuição dos informantes para a pesquisa, sobretudo dos não videntes, mostrou que os cegos possuem certa dificuldade com esse tipo de material, pois requer grande exercício de abstração, em um processo que vai da parte para o todo e náo o contrário.

Seria perfeitamente possível que um aluno cego compreendesse o desenho de uma cabeça, pois ele pode sentir a sua própria, todavia os elementos articuladores tornam isso uma tarefa árdua, pois são elementos, em sua maioria, com os quais não se tem contato visual, nem se pode, tampouco, tocá-los, e a mesma regra aplica-se à imagem que ilustra a abertura e fechamento da glote. Nesse sentido, a melhor forma encontrada pelos profissionais do CAP para representar a hemiface e os estados da glote foi a descrição.

O informante IV, que foi um dos responsáveis pela transposição das figuras em texto, afirmou que a descrição precisa ser clara e objetiva, livre de qualquer traço de subjetividade. Assim, a Figura 3 foi descrita como "Ilustração do aparelho fonador com identificação de todos os órgãos"; este texto aparece na versão adaptada dentro de um quadro. Em seguida, fora do quadro, foram elencados os articuladores utilizados na produção dos sons que, no livro em tinta, estão relacionados à figura por meio das setas, como se observa na Figura 3.

Já para representar a Figura 4, foi empregada a seguinte descrição: "Estados da glote com identificação das pregas vocais, glote aberta e fechada", que também apareceu em destaque dentro de um quadro. Vê-se que as descriçóes das imagens são sucintas e exigem, no momento da leitura do aluno não vidente, a presença do 
professor, que deverá assessorá-lo com as explicaçóes que forem necessárias para auxiliá-lo a compreender a imagem descrita.

Os exercícios e os quadros do livro em tinta foram transpostos para o livro em Braille normalmente, sem precisarem ser desfeitos, como é possível observar nas figuras a seguir com os quadros em tinta e em Braille dos fonemas vocálicos do português:

Quadro 1 - Fonemas vocálicos do português

\begin{tabular}{|l|c|c|c|}
\hline & anterior & central & posterior \\
\cline { 2 - 2 } & não-arred & & arred \\
\hline Alta & i ̃ & & u ũ \\
\cline { 1 - 2 } média-alta & e ã & & o ó \\
\hline média-baixa & $\varepsilon$ & & ว \\
\hline Baixa & & a ã & \\
\hline
\end{tabular}

Fonte: Antonio e Benites (2011, p. 40)

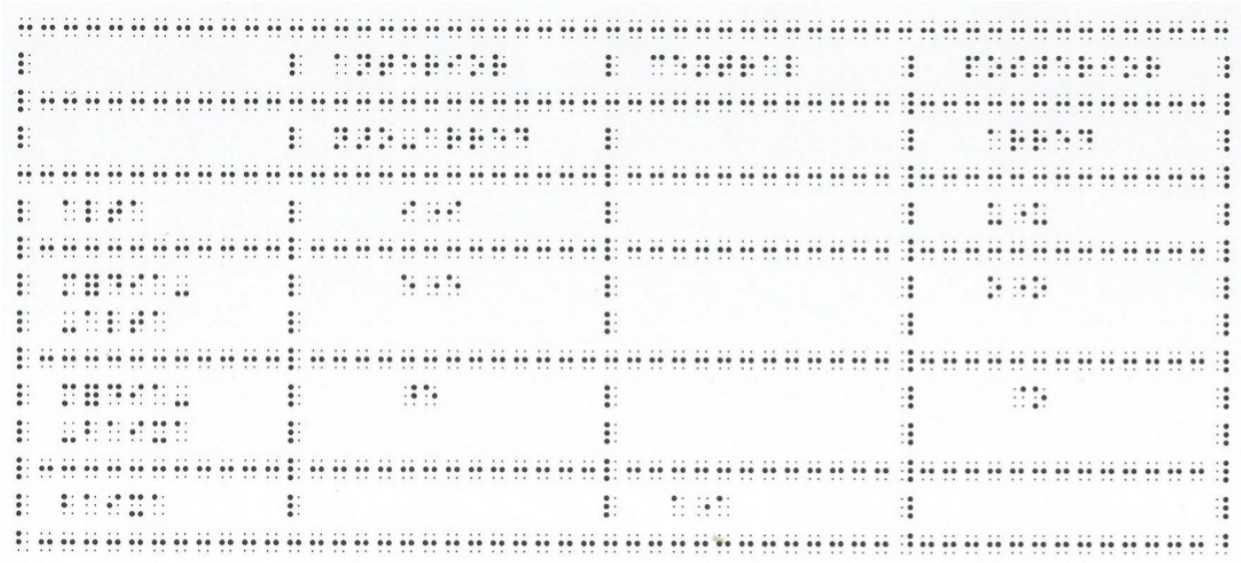

Figura 5 - Fonemas vocálicos do português na versão Braille Fonte: Elaborado pelos autores

Dentre as várias tabelas do material original, encontram-se os quadros de sons e fonemas consonantais e vocálicos, que trazem os símbolos fonéticos e fonológicos. Os símbolos foram transpostos para o Braille com uma cela ou a 
combinação de duas celas, por exemplo, a fricativa alveopalatal [3] foi adaptada como [j], enquanto a fricativa velar [x], como [" $\mathrm{r}]$.

Por solicitação dos pesquisadores, os adaptadores procuram manter o máximo de correspondência possível entre os símbolos do alfabeto fonético internacional e os adaptados. Assim, como pode ser visto no Quadro 2, aqueles que possuem correspondência com as letras do alfabeto, as quais têm representação em Braille, foram transpostos exatamente como aparecem no material em tinta. Os demais foram adaptados pelos profissionais do CAP e, nesse processo, segundo o informante IV, procuraram criar um símbolo inédito, mas que mantivesse alguma relação com o símbolo em tinta, feito por uma cela ou pela combinação de duas celas Braille entre colchetes ou barras. Procurou-se também estabelecer padrôes que facilitassem o agrupamento dos sons com a criaçáo de símbolos próximos, por exemplo, as diversas realizaçôes fonéticas dos fonemas vibrantes simples e múltiplo: tepe dental ou alveolar [,r], vibrante dental ou alveolar ['r], retroflexa dental ou alveolar $[\sim r$ ], fricativa velar desvozeada [“r], fricativa velar vozeada [_r], fricativa glotal desvozeada $[\mathrm{r}]$, fricativa glotal vozeada $[-\mathrm{r}]$.

Encontram-se no Capítulo 1, sobre fonética, quadros com sons consonantais, com os vocálicos e outras adaptaçôes das transcriçôes das semivogais que, em razão dos limites deste artigo, não serão apresentados. Pelo mesmo motivo, omitem-se aqui as adaptaçóes dos quadros dos fonemas consonantais, dos vocálicos e dos arquifonemas presentes no Capítulo 2, sobre fonologia.

No entanto, a título de exemplificação, apresenta-se a seguir um quadro com a representação dos sons consonantais do português brasileiro em tinta, Braille tinta e Braille: 
Quadro 2 - Sons consonantais do português brasileiro em tinta, Braille tinta e Braille

\begin{tabular}{|c|c|c|c|}
\hline Descrição & $\begin{array}{c}\text { Símbolo em } \\
\text { tinta }\end{array}$ & $\begin{array}{l}\text { Símbolo adap- } \\
\text { tado em tinta }\end{array}$ & $\begin{array}{l}\text { Símbolo adap- } \\
\text { tado em Braille }\end{array}$ \\
\hline Oclusiva bilabial desvozeada & [p] & [p] & : \\
\hline Oclusiva bilabial vozeada & {$[\mathrm{b}]$} & [b] & : : : : : \\
\hline Oclusiva dental desvozeada & {$[\mathbf{t}]$} & {$[\mathbf{t}]$} & : : : : : \\
\hline Oclusiva dental vozeada & [d] & [d] & : : : : : \\
\hline Oclusiva velar desvozeada & {$[\mathrm{k}]$} & {$[\mathrm{k}]$} & : : : : : \\
\hline Oclusiva velar vozeada & {$[\mathrm{g}]$} & {$[\mathrm{g}]$} & : : : : : : \\
\hline $\begin{array}{l}\text { Africada alveopalatal desvoze- } \\
\qquad a d a\end{array}$ & {$[\mathbf{t}]$} & {$[\mathbf{t x}]$} & : : : : : : : : \\
\hline Africada alveopalatal vozeada & [d3] & {$[\mathbf{d j}]$} & : : : : : : : \\
\hline Fricativa labiodental desvozeada & {$[\mathbf{f}]$} & [f] & : : : : : \\
\hline Fricativa labiodental vozeada & {$[\mathbf{v}]$} & {$[\mathbf{v}]$} & : : : : : \\
\hline Fricativa dental desvozeada & {$[s]$} & {$[s]$} & : : : : : : \\
\hline Fricativa dental vozeada & {$[\mathbf{z}]$} & {$[\mathbf{z}]$} & : : : : : \\
\hline $\begin{array}{l}\text { Fricativa alveopalatal desvoze- } \\
\qquad a d a\end{array}$ & {[]} & {$[\mathbf{x}]$} & : : : : : \\
\hline Fricativa alveopalatal vozeada & [3] & [j] & : : : : : \\
\hline Fricativa velar desvozeada & {$[\mathbf{x}]$} & [“'r] & : : : : : : : \\
\hline Fricativa velar vozeada & [y] & [_r $\mathbf{r}$ & : : : : : : : \\
\hline Fricativa glotal desvozeada & [h] & {$[\mathbf{r}]$} & : : : : : \\
\hline Fricativa glotal vozeada & [6] & {$[-\mathbf{r}]$} & : : : : : : : \\
\hline Nasal bilabial vozeada & {$[\mathbf{m}]$} & {$[\mathbf{m}]$} & : : : : : \\
\hline Nasal dental vozeada & [n] & [n] & : : : : : \\
\hline Nasal palatal vozeada & [n] & {$[, \mathbf{n}]$} & : : : : : : \\
\hline Tepe dental vozeado & {$[r]$} & {$[, \mathbf{r}]$} & : : : : : : : \\
\hline Vibrante dental vozeada & {$[\check{r}]$} & {$[\mathbf{r}]$} & : : : : : : \\
\hline Retroflexa dental vozeada & {$[\imath]$} & {$[\sim \mathbf{r}]$} & : : : : : : : : \\
\hline Lateral dental vozeada & {$[1]$} & [1] & : : : : : \\
\hline Lateral Palatal vozeada & {$[\Lambda]$} & ['1] & : : : : : : : \\
\hline
\end{tabular}

Fonte: Elaborado pelos autores

Romualdo, E.C.; Marques, G.S. O processo de produção/adaptação de material didático... 
Além dos quadros mencionados, o material original traz o alfabeto fonético internacional, porém ele não foi transposto para o adaptado, por trazer uma gama muito maior de símbolos, alguns muito díspares dos utilizados no Brasil, o que, de certa forma, confundiria os alunos não videntes.

O livro em tinta, em seu quarto capítulo, no qual a autora busca examinar algumas relaçôes entre fonologia e escrita e, também, permitir a reflexão sobre a relevância de tal conhecimento teórico para o ensino de língua portuguesa, apresenta alguns textos manuscritos de alunos com o intuito de exemplificar como a organizaçáo prosódica da linguagem pode influenciar na grafia. A seguir, temos a cópia de um desses textos manuscritos:

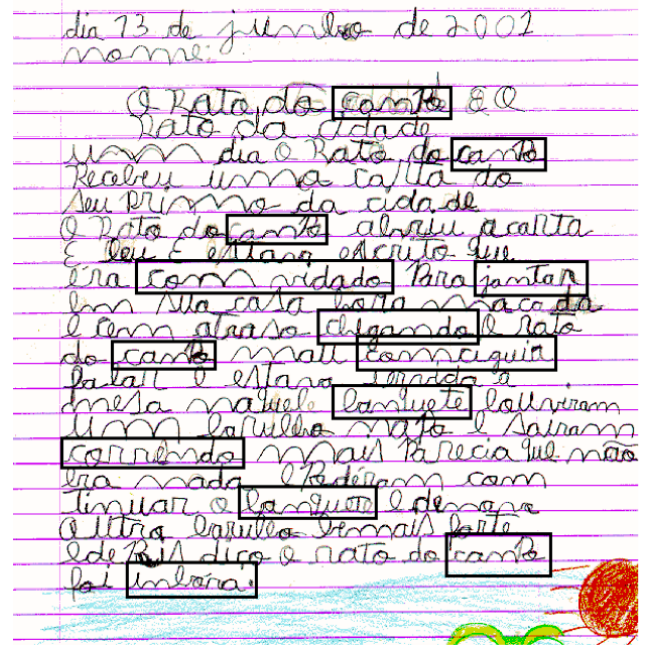

Figura 6 - Texto manuscrito infantil

Fonte: Antonio e Benites (2011, p. 74)

No livro adaptado, tais textos foram digitados da maneira como os alunos os escreveram, antecedidos pela descrição: "Texto manuscrito" e, quando havia palavras em destaque no original, os profissionais do CAP fizeram notas de transcrição para explicar que o negrito foi a forma de destaque que substituiu os quadros feitos em torno de algumas palavras dos textos originais.

O quinto capítulo da publicação tem por objetivo promover o reconhecimento de diferentes recursos expressivos no que tange aos conteúdos de fonética e fonologia e o funcionamento de tais recursos na produção de sentidos em diversos gêneros textuais. No decorrer do capítulo, o autor faz referência a 
uma experiência feita pelo psicólogo Wolfgang Köhler para saber se, na memória das pessoas, havia ligação entre formas visuais e certos sons. Esse experimento foi constituído por palavras inventadas em que se opunham sons consonantais desvozeados e vozeados - takete e maluma, as quais os participantes deveriam relacionar duas figuras que se opóem geometricamente:
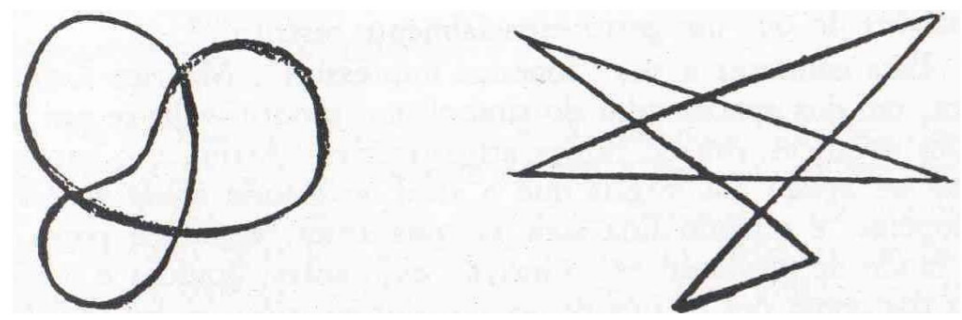

Figura 7 - Takete e maluma

Fonte: Antonio e Benites (2001, p. 90)

No material adaptado, essas figuras foram substituídas pela indicação "Figuras: material em relevo", visto que, diferentemente das Imagens 1 e 2, aquelas podem ser assim reproduzidas sem empecilhos, já que não são ricas em detalhes, pelo contrário, são figuras simples, de traço abstrato e marcadamente opostas. $\mathrm{O}$ objetivo é que o aluno as diferencie geometricamente: uma é curvilínea e a outra é angulosa. Isto pode ser feito pelo tato tranquilamente, o que torna o relevo, neste caso, o material ideal. O professor poderá utilizar, para a adaptação das figuras, qualquer forma de relevo, uma vez que as entrevistas mostraram a inexistência de uma forma melhor que a outra. É essencial, contudo, que a forma escolhida seja agradável ao tato, pois o aluno não vidente poderá manusear o material várias vezes.

O livro em tinta traz notas de rodapé que, no adaptado, apareceram no final do texto a que se referem, o que foi sinalizado pela seguinte nota de transcrição: “Todas as notas de rodapé estarão no final do texto". No segundo exercício do primeiro capítulo, que pede a indicação dos articuladores envolvidos na produção de um som que estará em negrito e a transcrição desse som, as letras em destaque foram colocadas, ao final de cada palavra, entre parênteses, o que foi marcado por outra nota de transcrição: "As letras em destaque estão escritas entre parênteses na frente da palavra para não confundir a leitura Braille".

É importante destacar que o material foi adaptado em um programa chamado "Braille Fácil", criado por José Antonio Borges, informático da UFRJ, mestre e doutor em Engenharia de Sistemas e Computação pela COPPE-UFRJ, para transcrever, automaticamente, documentos em texto para o Braille. Este software 
facilita a leitura dos não videntes, pois permite a impressão dos documentos em impressoras Braille de forma bastante rápida, podendo ser realizada com um mínimo de conhecimento da codificação Braille. O texto pode ser digitado diretamente no programa ou importado a partir de um editor de textos convencional.

O Braille Fácil utiliza os mesmos comandos de texto do Notepad ou Bloco de Notas do Windows, com algumas facilidades adicionais. $\mathrm{O}$ texto digitado pode ser visualizado e impresso em tinta ou em Braille. O software dá opçôes de inserção de elementos que embelezem o material produzido, como quadros para destacar algo no texto, por exemplo. O programa é composto de editor de textos integrador; editor gráfico para gráficos táteis; pré-visualizador da impressão Braille; impressor Braille automatizado; simulador de teclado Braille; utilitários para retoque em Braille; utilitários para facilitar a digitaçáo. Os direitos autorais do programa pertencem ao Instituto Benjamin Constant. Desta forma, qualquer pessoa com o arquivo do livro adaptado pode imprimi-lo em qualquer lugar, tornando-o acessível a todo aluno de Letras portador de necessidades especiais visuais.

O material foi impresso por uma das impressoras Braille do CAP, em papel sulfite de gramatura 40 , que é mais grosso que o comum, portanto mais resistente e durável.

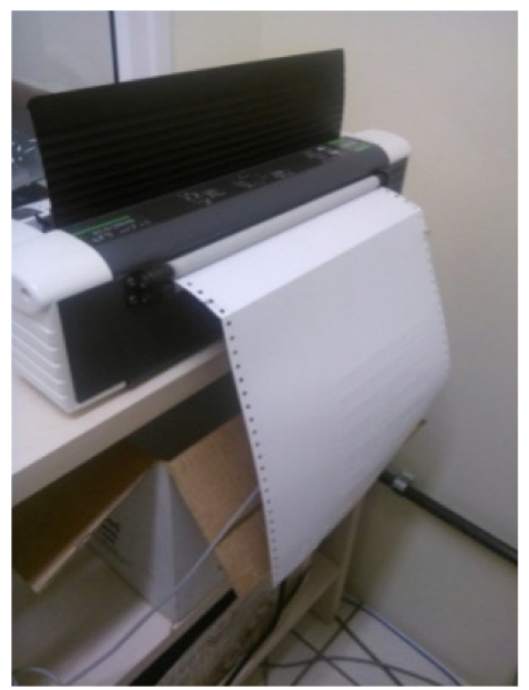

Figura 8 - Impressora Braille

Fonte: Elaborado pelos autores 
A impressão foi feita na frente e no verso das folhas, pois, segundo o informante IV, isso não constitui problema algum durante a leitura realizada pelo aluno cego. As duas apostilas foram encadernadas e, em sua primeira página, trazem o carimbo do CAP, em que constam endereço, telefone e e-mail para contato.

\section{CONCLUSÃO}

A partir das entrevistas realizadas com profissionais especialistas no ensino e aprendizagem de alunos com necessidades especiais visuais, vislumbrou-se o Braille como o melhor recurso para adaptar o livro sobre fonética e fonologia, por permitir a autonomia do aluno deficiente visual; por não exigir deste grande exercício de abstração; por ser agradável ao tato; e por poder ser reproduzido pelas impressoras Braille, garantindo a padronização e a produção em massa do material.

A autonomia do aluno aparece como primeiro fator, dado que é requisito das Diretrizes Curriculares do Curso de Letras (Brasil, 2001), e é importante considerar que o docente, na grande parte das vezes, não consegue dedicar tempo suficiente de sua aula ao discente com necessidades especiais, devido à quantidade de alunos que tem em sala e, também, ao conteúdo programático que precisa cumprir em carga horária determinada.

O segundo fator também é relevante, porque os materiais que exigem do aluno não vidente bagagens da memória visual são, de modo geral, ineficazes, uma vez que tanto a cegueira congênita quanto a adquirida fazem que os conceitos sejam vagos ou mesmo que se percam, com o passar do tempo. Isso toma proporçóes muito maiores quando se trata de representaçóes com as quais não se pode ter contato tátil, como é o caso dos elementos articuladores, envolvidos no processo de produção dos sons.

O terceiro fator aponta para a textura do recurso didático, se ela é ou não agradável ao tato. Isso se torna importante quando se imagina um aluno vidente ou não vidente - diante de novos conhecimentos. Leituras e releituras são processos indispensáveis, quanto sejam necessários, por isso um material de textura desagradável é contraindicado. A ideia é explicada quando se pensa no aluno vidente diante de um texto com letra reduzida, por exemplo, mas que é necessário ser lido demasiadas vezes, até que seja compreendido: a tarefa fica enfadonha e desgastante. É válido lembrar que muitas formas de relevo são agradáveis ao tato, mas, neste caso, esse fator foi somado aos outros três que, juntos, encaminharam a pesquisa ao Braille. 
A última razão mencionada, por fim, favorece o uso do Braille em detrimento de outras formas de relevo, porque estas náo garantem a padronização, ao contrário: por serem de natureza artesanal, não permitem cópias idênticas da mesma obra. Ademais, levam um tempo considerável de produção, o que não ocorre com os materiais em Braille, que podem ser adaptados em softwares especializados, como o Braille Fácil, e, em seguida, impressos rapidamente pelas impressoras Braille.

É essencial lembrar que, assim como o material em tinta, o adaptado trouxe várias formas de linguagem, não se limitando apenas ao Braille. Para cada elemento do texto original que se mostrou como um entrave no momento da transposição, os profissionais tomaram a medida que julgaram ser mais adequada e fizeram a devida adaptação, conforme sua experiência com alunos não videntes e, sobretudo, com a produçáo de material didático para tais. Seguindo as solicitaçóes dos pesquisadores, símbolos fonéticos e fonológicos foram adaptados para o Braille, as figuras mais complexas foram descritas, os textos manuscritos foram descritos e transcritos exatamente como aparecem nas fontes originais e as figuras de traço abstrato apresentaram a possibilidade do trabalho com o relevo.

Em linhas gerais, o relevo não é ineficaz, de forma alguma - para muitos materiais é a melhor opção. A pesquisa que subjaz a este artigo desmistificou a crença do senso comum de que todo e qualquer material para alunos deficientes visuais deve ser reproduzido, exclusivamente, em relevo, inclusive porque, ao se iniciar a pesquisa com influências dessa crença, o relevo era uma forte hipótese. Observouse que, assim como são heterogêneos os materiais, acabam o sendo também os recursos didáticos. A escolha do recurso deve ser pensada por profissionais que tenham experiência com não videntes e vivências que os reportem à forma como estes se comportam diante de um e de outro recurso didático.

Os questionamentos e pesquisa realizados por profissionais da UEM, unidos à experiência dos profissionais da educação especial, resultaram em um material inédito para o uso de acadêmicos de Letras não videntes. A pesquisa realizada mostra ainda que, embora haja uma legislação própria que assegure o atendimento aos alunos com necessidades especiais, em específico aos não videntes, as instâncias governamentais não proporcionam, muitas vezes, o suporte necessário ao docente que irá trabalhar com esses discentes. Nesse viés, a pesquisa teve papel importante, pois permitiu a ressignificação de um contexto em que o professor se via desamparado.

Espera-se com este artigo divulgar à comunidade acadêmica o resultado da pesquisa para que se coloque em discussão o material adaptado. Os pesquisadores 
da UEM responsáveis pela adaptação do material pretendem criar um grupo de alunos não videntes para aplicar o livro em Braille e, a partir de suas críticas e sugestôes, refiná-lo, se for preciso.

\section{REFERÊNCIAS}

Antonio JD, Benites SAL, organizadores. Fonética e fonologia. Maringá: EDUEM; 2011.

Baptista JALS. A invenção do Braille e sua importância na vida dos cegos. Lisboa: Gráfica 2000. 9 p. [citado em 9 out. 2014]. Disponível em: http://www.gesta.org/braille/braille01. htm.

Brasil. Conselho Nacional de Educação. Conselho Pleno. Resolução CNE/CP n. 1 de 18 de fevereiro de 2002. Institui Diretrizes Curriculares Nacionais para a Formaçâo de Professores da Educação Básica, em nível superior, curso de licenciatura, de graduação plena. Presidente: Ulysses de Oliveira Panisset. [citado em 19 nov. 2014]. Disponível em: http:// portal.mec.gov.br/seesp/arquivos/pdf/res1_2.pdf

Brasil. Ministério Público Federal; Fundação Procurador Pedro Jorge de Melo e Silva, organizadores. $\mathrm{O}$ acesso de alunos com deficiência às escolas comuns da rede regular. $2^{\mathrm{a}}$ ed. Brasília: Ministério Público Federal; 2014. [citado em 19 nov. 2014]. Disponível em: http://www.adiron.com.br/arquivos/cartilhaatual.pdf

Brasil. Ministério da Educaçâo. Braille Fácil 3.5a. [citado em20 abr. 2015]. Disponível em: http://intervox.nce.ufrj.br/brfacil/

Brasil. Ministério da Educação. Lei n. 9.394 de 20 dezembro de 2006. Diretrizes e Bases da Educação Nacional. Brasília (1996 dez. 20). [citado em 21 maio 2014]. Disponível em: http://www.planalto.gov.br/ccivil_03/leis/19394.htm

Brasil. Ministério da Educação. Conselho Nacional de Educação. Parecer CNE/CP 9/2001 de 18 de janeiro de 2002. Diretrizes Curriculares Nacionais para a Formação de Professores da Educação Básica, em nível superior, curso de licenciatura, de graduação plena. Diário Oficial da União, Brasília (2002 jan. 18). [citado em 21 maio 2014]. Disponível em: http:// portal.mec.gov.br/cne/arquivos/pdf/009.pdf

Brasil. Ministério da Educação. Parecer CNE/CES 492/2001. Diretrizes Curriculares Nacionais dos cursos de Filosofia, História, Geografia, Serviço Social, Comunicação Social, Ciências Sociais, Letras, Biblioteconomia, Arquivologia e Museologia. Diário Oficial da União, Brasília (2001 jul. 9). [citado em 6 abr. 2014]. Disponível em: http://portal.mec. gov.br/cne/arquivos/pdf/CES0492.pdf

Romualdo, E.C.; Marques, G.S. O processo de produção/adaptação de material didático... 
Brasil. Ministério da Educação. Dispóe sobre requisitos de acessibilidade de pessoas portadoras de deficiências, para instruir os processos de autorização e de reconhecimento de cursos, e de credenciamento de instituiçóes. Portaria n. 1.679 de2 dezembro de 1999. [citado em 21 maio 2014]. Disponível em: http://portal.mec.gov.br/sesu/arquivos/pdf/c1_1679.pdf

Brasil. Decreto n. 2.306 de 19 de agosto de 1997. Brasília (1997 ago. 19). [citado em 21 maio 2014]. Disponível em: http://www2.camara.leg.br/legin/fed/decret/1997/ decreto-2306-19-agosto-1997-437195-publicacaooriginal-1-pe.html

Brasil. Lei n. 9.131 de 24 de novembro de 1995. Brasília (1995 nov. 24). [citado em 21 maio 2014]. Disponível em: http://www.planalto.gov.br/ccivil_03/leis/19131.htm

Callou D, Leite Y. Iniciação à fonética e à fonologia. 2a ed. Rio de Janeiro: Jorge Zahar; 1993.

Câmara Jr. JM. Estrutura da língua portuguesa. 7a ed. Petrópolis: Vozes; 1976.

Kassar MCM. Educação especial na perspectiva da educação inclusiva: desafios da implantação de uma política nacional. Educar em Revista. Curitiba, n. 41, p. 61-79, jul./ set. 2011, EDUFPR. [citado em 18 fev. 2015]. Disponível em: http://www.scielo.br/pdf/ er/n41/05.pdf

Manzini EJ. Entrevista semi-estruturada: análise de objetivos e roteiros. In: Seminário Internacional sobre pesquisa e estudos qualitativos, 2, 2004, Bauru. A pesquisa qualitativa em debate. Anais. Bauru: USC; 2004. CD-ROM. [citado em 23 maio 2014]. Disponível em: http://www.marilia.unesp.br/Home/Instituicao/Docentes/EduardoManzini/

Manzini_2004_entrevista_semi-estruturada.pdf

Silva TC. Fonética e fonologia do português: roteiro de estudos e guia de exercícios. $6^{\mathrm{a}}$ ed. São Paulo: Contexto; 2002.

Triviños ANS. Entrevista semiestruturada como técnica de coleta de informaçóes. In: Triviños ANS. Introdução à pesquisa em ciências sociais: a pesquisa qualitativa em educação. $1^{\text {a }}$ ed., $21^{\text {a }}$ reimpr. São Paulo: Atlas; 2012. p. 145-152.

Recebido em: 15/06/2015

Aceito em: 06/11/2015

Romualdo, E.C.; Marques, G.S. O processo de produção/adaptação de material didático... 